\title{
Risk of Diabetes Mellitus Associated with Atypical Antipsychotic Use Among Medicaid Patients with Bipolar Disorder: A Nested Case-Control Study
}

\author{
Jeff J. Guo, Ph.D., Paul E. Keck, Jr., M.D., Patricia K. Corey-Lisle, Ph.D., Hong Li, Ph.D., \\ Dongming Jiang, Ph.D., Raymond Jang, Ph.D., and Gilbert J. LItalien, Sc.D.
}

Study Objective. To quantify the risk of diabetes mellitus associated with atypical antipsychotics compared with conventional antipsychotics in managed care Medicaid patients with bipolar disorder.

Design. Retrospective nested case-control study.

Data Source. Integrated seven-state Medicaid managed care claims database from January 1, 1998-December 31, 2002.

Patients. Two hundred eighty-three patients with diabetes (cases) and 1134 controls matched by age, sex, and the index date on which bipolar disorder was diagnosed.

Measurements and Main Results. Cases were defined as those having an International Classification of Diseases, Ninth Revision diagnosis of diabetes or those receiving treatment with antidiabetic drugs. Both case and control patients had at least a 3-month exposure to either conventional or atypical antipsychotic agents or three filled prescriptions related to treatment for bipolar disorder. Of the 283 cases, 139 (49\%) received atypical antipsychotics (olanzapine, risperidone, quetiapine, ziprasidone, and clozapine) and 133 (47\%) were prescribed conventional antipsychotics. To compare the risk for new-onset diabetes associated with atypical versus conventional antipsychotics, we conducted a Cox proportional hazard regression, in which we controlled for age; sex; duration of bipolar disorder follow-up; use of lithium, anticonvulsants, antidepressants, and other drugs; and psychiatric and medical comorbidities. Compared with patients receiving conventional antipsychotics, the risk of diabetes was greatest among patients taking risperidone (hazard ratio [HR] 3.8, 95\% confidence interval [CI] 2.7-5.3), olanzapine (3.7, 95\% CI 2.5-5.3), and quetiapine (2.5, 95\% CI 1.4-4.3). The risk for developing diabetes was also associated with weight gain (HR 2.5, 95\% CI 1.9-3.4), hypertension (HR 1.6, 95\% CI 1.2-2.2), and substance abuse (HR 1.5, 95\% CI 1.0-2.2).

Conclusion. Olanzapine, risperidone, and quetiapine are all associated with development or exacerbation of diabetes mellitus in patients with bipolar disorder. When prescribing therapy for this patient population, metabolic complications such as diabetes, weight gain, and hypertension need to be considered.

Key Words: diabetes, bipolar disorder, atypical antipsychotics, managed care, Medicaid.

(Pharmacotherapy 2007;27(1):27-35)

Traditionally, mood stabilizers such as lithium, divalproex, and carbamazepine have been the primary agents used to treat bipolar disorder. Although conventional antipsychotics also have 
been prescribed to treat acute mania, long-term maintenance use of these agents is limited due to their intolerable adverse events, including akathisia, extrapyramidal symptoms, and tardive dyskinesia. Atypical antipsychotics (aripiprazole, clozapine, olanzapine, quetiapine, risperidone, and ziprasidone) are generally regarded as having lower risk for causing extrapyramidal symptoms than conventional antipsychotics; they have been used with increasing frequency in the treatment of bipolar disorder since the mid-1990s. ${ }^{1-4}$ This trend may reflect the antimanic or moodstabilizing properties of atypical antipsychotics and their favorable tolerability profiles compared with conventional agents. ${ }^{5-7}$ Recent clinical trials suggest that antipsychotic augmentation might be efficacious for treatment of bipolar depression. ${ }^{7-9}$ Unfortunately, atypical antipsychotics are associated with metabolic complications that place patients at risk for weight gain, altered glucose metabolism, dyslipidemia, myocarditis, and cardiomyopathy. ${ }^{10-13}$

The increased risk for diabetes associated with atypical antipsychotics may reflect direct effects of these drugs on $\beta$-cell function and insulin action. $^{10,11}$ Several published studies, including a number of retrospective cohort studies, have shown associations between the development of diabetes or glucose intolerance and the atypical antipsychotics clozapine, olanzapine, and risperidone in patients with schizophrenia. ${ }^{14-23} \mathrm{~A}$ research group reported hazard ratios (HRs) for diabetes risk of 1.1-1.2 in Veterans Affairs patients who received atypical antipsychotics. ${ }^{24}$ Two groups in the United Kingdom found that atypical antipsychotics were associated with HRs

From the College of Pharmacy, University of Cincinnati Medical Center, Cincinnati, Ohio (Drs. Guo and Jang); the Institute for Health Policy and Health Services Research, University of Cincinnati, Cincinnati, Ohio (Dr. Guo); the Department of Psychiatry, University of Cincinnati College of Medicine, Cincinnati, Ohio (Dr. Keck); the Mental Health Care Line and General Clinical Research Center, Cincinnati Veterans Affairs Medical Center, Cincinnati, Ohio (Dr. Keck); Bristol-Myers Squibb Pharmaceutical Research Institute, Wallingford, Connecticut (Drs. Corey-Lisle, Li, and L'Italien); and the Biostatistics Division, GlaxoSmithKline Pharmaceutical, Philadelphia, Pennsylvania (Dr. Jiang).

Presented at the International Conference of Pharmacoepidemiology, Bordeaux, France, August 20-25, 2004.

Supported by a grant from the Bristol-Myers Squibb Pharmaceutical Research Institute, Wallingford, Connecticut.

Address reprint requests to Jeff J. Guo, Ph.D., University of Cincinnati Medical Center, 3225 Eden Avenue, Cincinnati, OH 45267-0004; e-mail: jeff.guo@uc.edu. for diabetes of 4.7-5.8. ${ }^{24,25}$ An analysis based on the World Health Organization's adverse drug reaction database found that these agents had an HR for diabetes as high as $10.22 .{ }^{26}$ Several cases of diabetic ketoacidosis and diabetes associated with atypical antipsychotics have been reported among adult ${ }^{27}$ and pediatric ${ }^{28,29}$ patients with bipolar disorder. Although atypical antipsychotics are widely used to treat mania, their association with diabetes onset has not been adequately quantified in patients with bipolar disorder. ${ }^{30}$

Not only is the Medicaid program the dominant payer for mental health services in the United States, ${ }^{31}$ but the number of Medicaid enrollees in managed care organizations has increased since the mid-1990s. ${ }^{32}$ Studies using Iowa and California Medicaid claims databases have found that patients with schizophrenia exposed to clozapine or olanzapine were at increased risk for type 2 diabetes. ${ }^{33,} 34$ Yet, very little information exists about the risk of diabetes associated with antipsychotic drug use among patients with bipolar disorder in the managed care Medicaid population.

We hypothesized that atypical antipsychotics would present a different risk for diabetes than conventional antipsychotics. Our objectives were to investigate the association between atypical antipsychotics and diabetes mellitus in patients with bipolar disorder in the managed care Medicaid population and compare it with the association between conventional antipsychotics and diabetes in the same patient population. In assessing the risk for diabetes, we controlled for key covariates such as age, sex, and psychiatric and medical comorbidities, as well as concomitant drugs that affect patients' risk for hyperglycemia.

\section{Methods}

\section{Data Source}

Our data source was a multistate managed care claims database (PharMetrics, Watertown, MA). The database covered over 45 million individuals enrolled in managed care organizations with 70 health plans, including seven state Medicaid managed care programs, in four U.S. regions: Midwest (34.1\%), East (15.6\%), South (23.9\%), and West $(26.4 \%){ }^{35}$ The database included each patient's date of enrollment and pharmacy, medical, and institutional claims. Each medical claim was recorded with accompanying diagnostic codes from the International Classification of Diseases, Ninth Revision (ICD-9) that justified 
the medical service. This geographically diversified claims database provides a large quantity of health information pertaining to the Medicaid population. The use of Medicaid or managed care claims databases for pharmacoepidemiologic studies has been well documented. ${ }^{14,23,24,33,34}$

\section{Study Design}

We used a retrospective nested case-control (population-based case-control) design. Claims data from January 1, 1998-December 31, 2002 (5 calendar years) were reviewed. To protect patient confidentiality, we deleted patient names, insurance plan identification numbers, and other patient identifiers from the claims database. Randomized patient numbers and patients' birth years were used for identification and calculation of age. The research project was approved by the University of Cincinnati Medical Center's institutional review board.

\section{Study Cohort Identification}

As shown in Figure 1, from 1998-2002 a total of 48,965 managed care Medicaid patients had at least one diagnosis of an affective disorder (ICD9 code 296.xx) or cyclothymia (ICD-9 code 301.13). We excluded 4841 patients with schizophrenia (295.xx), 30,624 patients with depression only (296.2x and/or 296.3x), and 29 patients aged 65 years or greater during the study period. These exclusions enabled us to assess patients with bipolar disorder while avoiding confounding due to patients who had schizophrenia and/or depression or who were eligible for both Medicare and Medicaid. The final cohort consisted of 13,471 patients with bipolar disorder indicated by any of the following ICD-9 codes: 296.0, 296.1, and 296.4-296.8. Because less than $0.1 \%$ of the study group had cyclothymia, patients with that disorder were not categorized separately.

In keeping with other published retrospective cohort studies, ${ }^{15-25}$ we selected a cohort of patients who had a minimum of 3 months of exposure to atypical or conventional antipsychotics or at least three filled prescriptions related to treatment of bipolar disorder during the study period. Incident cases of diabetes were identified by either the earliest diagnosis of ICD9 code 250.xx or treatment for diabetes after the first identified use of antipsychotics. The date for the first diabetes diagnosis or first use of antidiabetic drugs was defined as the diabetes index date. To ensure that we were identifying incident cases of diabetes, we checked medical and prescription claim records for any diagnosis or treatment of diabetes before the diabetes index date. Patients were rejected as cases if they had a prescription for oral antidiabetic agents before the diabetes index date. The oral antidiabetic agents identified were sulfonylurea drugs (acetohexamide, glipizide, glyburide), a biguanide (metformin), thiazolidinediones (pioglitazone, rosiglitazone), $\alpha$-glucosidase inhibitors (acarbose, miglitol), and the new drugs repaglinide and nateglinide.

The index date of bipolar diagnosis was the first date of diagnosis indicated by designated ICD-9 codes for bipolar disorder during the study period. For each case we matched five controls according to age at bipolar diagnosis index date (standard deviation of $5 \mathrm{yrs}$ ), sex, and the month and year of diagnosis of bipolar disorder. Controls meeting the matching criteria were selected at random using SAS, version 8.0 (SAS Institute Inc., Cary, NC), software. Controls were selected from a population of patients who had been diagnosed with bipolar disorder but were not diagnosed with or treated for diabetes at any time during the study period. Because the

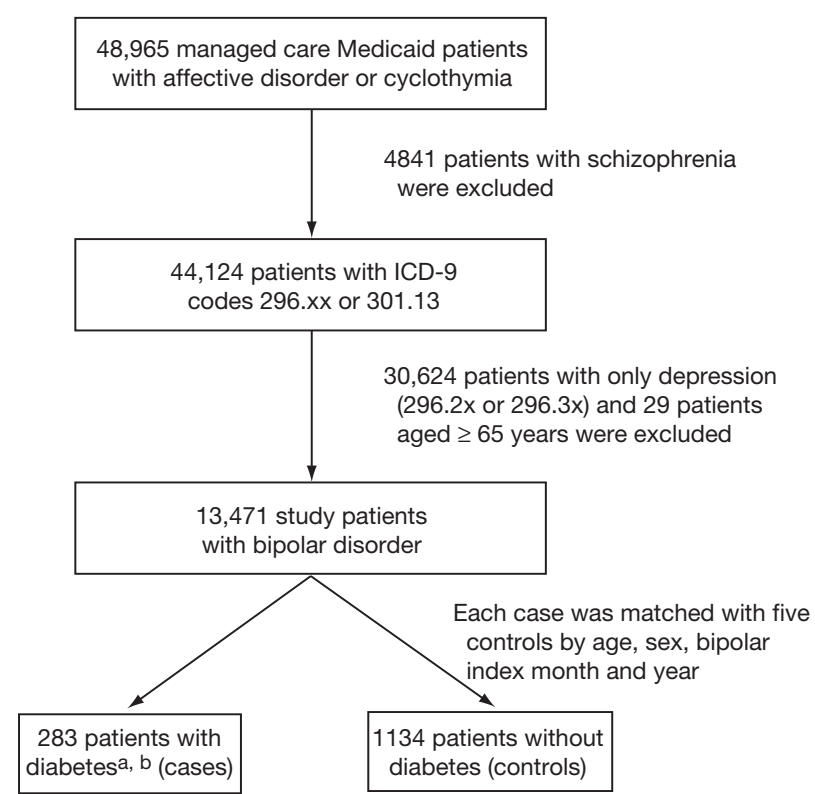

Figure 1. Patient flow diagram of incident cases of diabetes mellitus and controls from patients with bipolar disorder in the United States managed care Medicaid population,

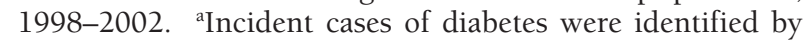
either earliest diagnosis of International Classification of Diseases, Ninth Revision (ICD-9) code 250.xx or treatment for diabetes. ${ }^{b}$ Eighty-nine case patients with fewer than five matched controls were included in the analysis. 
month and year of bipolar diagnosis were part of the matching criteria, the calendar time distributions of the bipolar index date were the same for both cases and controls.

\section{Drug Use and Covariates}

We classified antipsychotics as either conventional or atypical. The atypical antipsychotics were olanzapine, risperidone, quetiapine, ziprasidone, and clozapine. Aripiprazole was not included in this analysis as it was not available during the study period. The conventional antipsychotics were haloperidol, chlorpromazine, fluphenazine, loxapine, molindone, perphenazine, thioridazine, trifluoperazine, thiothixene, and pimozide. Other antipsychotics, such as thioxanthenes (flupenthixol, zuclopenthixol), pipotiazine, and methotrimeprazine were not included in this study because they were not available in the United States.

Published reports indicate that some drugs elevate blood glucose levels in some patients. Thus, our analysis incorporated data on administration of any of the following drugs during the study period: $\alpha$-blockers (e.g., doxazosin, prazosin, terazosin), $\beta$-blockers (e.g., atenolol, betaxolol, bisoprolol), thiazide diuretics (e.g., chlorothiazide, chlorthalidone, polythiazide), corticosteroids (e.g., methylprednisolone, hydrocortisone), phenytoin, oral contraceptives containing norgesterol, and valproic acid. ${ }^{30,36,37}$

For both cases and controls, all prescription drug claims for treatment of bipolar disorder and diabetes were abstracted and reviewed. The follow-up period began with each patient's first bipolar diagnosis date and ended with the index date of diabetes, the end of the study period, or the end of the patient's enrollment in the managed care Medicaid program, whichever came first. We used dichotomous variables to indicate whether a patient had received concomitant drugs known to be associated with diabetes or hyperglycemia. All drug claims were identified by national drug codes.

In addition to drugs known to affect the risk of diabetes, we adjusted the analysis for psychiatric comorbidities (alcohol abuse, substance abuse disorder, personality disorder, anxiety disorder, and impulse-control disorder) and medical comorbidities (hypertension, weight gain, arthritis, cerebral vascular disease, chronic obstructive pulmonary disease, dyslipidemia, and coronary heart disease. The ICD-9 codes were used to identify comorbid conditions from either hospital or clinical encounters.
Statistical Analysis

All analyses were performed with SAS, version 8.0. Descriptive statistics were used to explore patient demographics and drug use categories. The age of each patient was simply the age at bipolar diagnosis. We conducted the Cox proportional hazard regression to assess the risk for diabetes associated with antipsychotic drugs due to the consideration of time-to-event with censoring and covariates. We determined hazard ratios for each risk factor with $95 \%$ confidence intervals. Patients taking conventional antipsychotics were the referent group in our comparison of diabetes risk among patients.

\section{Results}

Table 1 summarizes the characteristics of the study population. During the 5-year study period (1998-2002), of the 13,471 managed care Medicaid patients with bipolar disorder, 1730 (13\%) had at least one prescription for atypical antipsychotics, 1918 (14\%) had prescriptions for conventional antipsychotics, 1048 (8\%) for lithium, 3013 (22\%) for anticonvulsants, and 4011 (30\%) for antidepressants.

The first cohorts we selected consisted of 323 case patients who developed diabetes after the bipolar index date and after their first antipsychotic drug exposure and 12,432 control patients who had bipolar disorder but not diabetes during the study period. We then excluded eight case patients who received insulin for type 1 diabetes and 32 case patients who were unmatched with controls. This resulted in 283 cases of diabetes and matched 1134 controls. Eighty-nine cases that had fewer than five controls/case were kept for the study. Most of those cases were adults older than 50 years. The age and sex of these cases and controls were similar.

As shown in Table 1, treatment with atypical antipsychotics, conventional antipsychotics, lithium, anticonvulsant drugs, and antidepressant drugs was more prevalent among cases than controls. Of the 283 cases, 133 (47\%) received conventional antipsychotics, and 139 (49\%) received atypical antipsychotics. Because only five patients $(<2 \%)$ received more than one atypical antipsychotic during the study period, we did not categorize this patient group.

Compared with patients receiving conventional antipsychotics, the risk for diabetes was greatest among patients taking risperidone (HR 3.8, 95\% CI 2.7-5.3), olanzapine (HR 3.7, 95\% CI 
Table 1. Characteristics of the Study Patients

\begin{tabular}{|c|c|c|}
\hline \multirow[b]{2}{*}{ Characteristic } & \multicolumn{2}{|c|}{ No. (\%) of Patients } \\
\hline & $\begin{array}{c}\text { Cases } \\
(\mathrm{n}=283)\end{array}$ & $\begin{array}{c}\text { Controls } \\
(\mathrm{n}=1134)\end{array}$ \\
\hline \multicolumn{3}{|l|}{ Age (yrs) } \\
\hline$\leq 12$ & $5(1.77)$ & $25(2.20)$ \\
\hline $13-17$ & $10(3.53)$ & $50(4.41)$ \\
\hline $18-34$ & $70(24.73)$ & $329(29.01)$ \\
\hline $35-49$ & $129(45.58)$ & $562(49.56)$ \\
\hline $50-64$ & $69(24.38)$ & $168(14.81)$ \\
\hline \multicolumn{3}{|l|}{ Sex } \\
\hline Female & $227(80.21)$ & $916(80.78)$ \\
\hline Male & $56(19.79)$ & $218(19.22)$ \\
\hline \multicolumn{3}{|l|}{ Psychotherapeutic drugs ${ }^{\text {a }}$} \\
\hline Lithium & $153(54.06)$ & $119(10.49)$ \\
\hline Anticonvulsants ${ }^{\mathrm{b}}$ & $164(57.95)$ & $289(25.48)$ \\
\hline Atypical antipsychotics & $139(49.12)$ & $164(14.46)$ \\
\hline Olanzapine & $51(18.02)$ & $79(6.97)$ \\
\hline Quetiapine & $18(6.36)$ & $20(1.76)$ \\
\hline Risperidone & $65(22.97)$ & $61(5.38)$ \\
\hline Ziprasidone & $2(0.71)$ & $3(0.26)$ \\
\hline Clozapine & $3(1.06)$ & $2(0.18)$ \\
\hline Antidepressants & $174(61.48)$ & $374(32.98)$ \\
\hline Conventional antipsychotics & $133(47.00)$ & $213(18.78)$ \\
\hline \multicolumn{3}{|l|}{ Other concomitant drugs ${ }^{\mathrm{a}}$} \\
\hline$\beta$-Blockers & $63(22.26)$ & $86(7.58)$ \\
\hline$\alpha$-Blockers & $4(1.41)$ & $7(0.62)$ \\
\hline Corticosteroids & $78(27.56)$ & $171(15.08)$ \\
\hline Thiazide diuretics & $30(10.60)$ & $38(3.35)$ \\
\hline Oral contraceptives & $9(3.18)$ & $17(1.50)$ \\
\hline Valproic acid & $1(0.35)$ & $8(0.71)$ \\
\hline Phenytoin & $5(1.76)$ & $18(1.59)$ \\
\hline \multicolumn{3}{|l|}{ Psychiatric comorbidities $^{c}$} \\
\hline Alcohol abuse & $22(7.77)$ & $147(12.96)$ \\
\hline Substance abuse & $41(14.48)$ & $146(12.87)$ \\
\hline Anxiety disorder & $150(53.00)$ & $445(39.24)$ \\
\hline Impulse-control disorder & $5(1.76)$ & $22(1.94)$ \\
\hline Personality disorder & $21(7.42)$ & $65(5.73)$ \\
\hline \multicolumn{3}{|l|}{ Medical comorbidities ${ }^{c}$} \\
\hline Hypertension & $130(45.94)$ & $194(17.11)$ \\
\hline Weight gain & 79 (27.92) & $90(7.94)$ \\
\hline Arthritis & $16(5.65)$ & $30(2.65)$ \\
\hline \multicolumn{3}{|l|}{ Chronic obstructive } \\
\hline pulmonary disease & $41(14.49)$ & $71(6.26)$ \\
\hline Cerebral vascular disease & $15(5.30)$ & $27(2.38)$ \\
\hline Coronary heart disease & $11(3.88)$ & $5(0.44)$ \\
\hline Dyslipidemia & $8(2.83)$ & $5(0.44)$ \\
\hline
\end{tabular}

2.5-5.3), quetiapine ( $\operatorname{HR} 2.5,95 \%$ CI 1.4-4.3), and the anticonvulsants divalproex and carbamazepine (HR 1.6, 95\% CI 1.2-2.1; Table $2)$. These data were obtained in a process that controlled for the covariates of age, sex, and duration of follow-up; use of lithium, anticonvulsants, and antidepressants; concomitant drugs (not related to bipolar disorder); and psychiatric and medical comorbidities. In addition, patients whose bipolar disorder was coupled with substance abuse, hypertension, and/or weight gain had a significantly higher risk for diabetes than their counterparts.

\section{Discussion}

This multistate, population-based, nested casecontrol study examined the risk of diabetes 
associated with use of antipsychotics in Medicaid patients with bipolar disorder. After controlling for personal risk factors and concomitant drug use, we found that patients receiving atypical antipsychotics for bipolar disorder are at increased risk for diabetes. Our findings add to the body of observational evidence indicating that certain atypical antipsychotics may be associated with an increased risk for diabetes among patients with bipolar disorder. ${ }^{27-29}$ It is unclear, however, whether the diabetes in the study population is due to the use of atypical antipsychotics versus the underlying condition of bipolar disorder versus characteristics of the Medicaid population, such as low socioeconomic status, poor overall physical health, unhealthy lifestyles, and poor access to health care services.

Atypical antipsychotics are generally regarded as having less potential for causing extrapyramidal symptoms and a higher serotonin:dopamine receptor affinity compared with conventional antipsychotics. ${ }^{11,12}$ Recent literature indicates that clozapine, olanzapine, and risperidone are more likely to be associated with diabetes (indicated by diabetic ketoacidosis and an atherogenic lipid profile) than other atypical agents. ${ }^{14,28,29,38,39}$ One possible mechanism for hyperglycemia is impairment of insulin resistance, which may occur because of weight gain or a change in body fat distribution or by a direct effect on insulin-sensitive target tissues. ${ }^{2,10,11}$

Our findings are comparable to data from published pharmacoepidemiologic studies of patients with schizophrenia. ${ }^{14,23-25}$ For example, reported HRs for diabetes in patients with schizophrenia were 1.2-5.8 for olanzapine and 1.1-2.2 for risperidone. ${ }^{14,23-25,33}$ These values can be compared with the HRs we obtained for the same drugs in patients with bipolar disorder: HR 3.7 (95\% CI 2.5-5.3) for olanzapine and 3.8 (95\% CI 2.7-5.3) for risperidone (Table 2). After controlling for comorbidities, personal risk factors, and concomitant drugs, we also found that quetiapine increases the risk for diabetes in patients with bipolar disorder (HR 2.5, 95\% CI 1.4-4.4). Although quetiapine has been linked to diabetes in case reports, ${ }^{40-43}$ earlier studies have failed to confirm this association. ${ }^{33}$ This may be due to their small sample sizes or lack of control for confounding variables. ${ }^{44}$ The HRs associated with clozapine (HR 2.9, 95\% CI 0.9-9.6) and ziprasidone (HR 4.3, 95\% CI 1.0-18.9) in our study were large, but they were not statistically significant. This might be due to the small number of patients in our study who received either clozapine or ziprasidone. Longterm data from large, randomized, controlled trials are needed to more explicitly examine the association between diabetes and various atypical antipsychotic drugs.

As shown in Table 2, in addition to antipsychotic use, diabetes risk is also associated with weight gain and hypertension. As the literature indicates, olanzapine, clozapine, and risperidone are associated with weight gain, ${ }^{13,45,46}$ hyperlipidemia, and hypertriglyceridemia, all of which are independent risk factors for heart disease. ${ }^{14,47,48}$ Our findings of elevated HRs for weight gain and hypertension make it likely that the incident cases of diabetes we identified were associated with metabolic syndrome. Our data also show that patients with substance abuse have a heightened risk for diabetes. It is possible that these patients might have less healthy lifestyles, poorer drug compliance, or poorer access to health care services than patients without substance abuse. ${ }^{49,50}$ Poor drug compliance might lead to drug overdose, which could increase the risk for diabetes in this population. ${ }^{33}$

Our study had several limitations. Children, women, and low-income populations are overrepresented in the Medicaid population. Thus, our findings might not be indicative of the general population. We inferred drug use from automated pharmacy claims data. Although baseline drug use differed between cases and controls, we tried to adjust for these differences with the Cox proportional hazard model. Because of the retrospective nature of a claims database review, we could not assess individual patients with regard to severity of bipolar disorder, socioeconomic class, lipid profiles, fasting glucose concentrations, or changes in body mass index related to weight gain.

Moreover, data on patients' ethnicity were missing when PharMetrics (data vendor) collected medical claims information from participating managed care organizations. Another concern is that clinicians may have prescribed one drug versus another based on patients' specific symptoms. We attempted to reduce this potential confounding bias by adjusting for known concomitant drugs and comorbidities. We also included dyslipidemia and coronary heart disease as comorbidities, as these provide a rough proxy for patients at high risk for diabetes. It is possible that we underestimated the prevalence of diabetes due to our study's limited time window, changes in 
Table 2. Hazard Ratios for Diabetes Risk

\begin{tabular}{|c|c|c|}
\hline Variable & Hazard Ratio $^{a}$ & $95 \% \mathrm{CI}$ \\
\hline $\begin{array}{l}\text { Pyschotherapeutic drugs } \\
\text { Conventional antipsychotic } \\
\text { Olanzapine } \\
\text { Quetiapine } \\
\text { Risperidone } \\
\text { Ziprasidone } \\
\text { Clozapine } \\
\text { Lithium } \\
\text { Anticonvulsant } \\
\text { Antidepressant }\end{array}$ & $\begin{array}{l}1.000 \\
3.664 \\
2.476 \\
3.771 \\
4.297 \\
2.872 \\
1.016 \\
1.571 \\
1.138\end{array}$ & $\begin{array}{l}1.000 \\
2.542-5.281 \\
1.427-4.296 \\
2.699-5.269 \\
0.976-18.923 \\
0.862-9.575 \\
0.729-1.416 \\
1.153-2.140 \\
0.842-1.538\end{array}$ \\
\hline $\begin{array}{l}\text { Other concomitant drugs } \\
\beta \text {-Blocker } \\
\alpha \text {-Blocker } \\
\text { Corticosteroid } \\
\text { Thiazide diuretic } \\
\text { Oral contraceptive } \\
\text { Valproic acid } \\
\text { Phenytoin }\end{array}$ & $\begin{array}{l}1.329 \\
0.669 \\
1.048 \\
1.254 \\
1.766 \\
0.359 \\
0.428\end{array}$ & $\begin{array}{l}0.960-1.839 \\
0.235-1.907 \\
0.775-1.417 \\
0.807-1.947 \\
0.829-3.761 \\
0.049-2.640 \\
0.167-1.098\end{array}$ \\
\hline $\begin{array}{l}\text { Psychiatric comorbidities } \\
\text { Alcohol abuse } \\
\text { Substance abuse } \\
\text { Anxiety disorder } \\
\text { Impulse-control disorder } \\
\text { Personality disorder }\end{array}$ & $\begin{array}{l}0.623 \\
1.491 \\
1.257 \\
0.499 \\
1.096\end{array}$ & $\begin{array}{l}0.390-0.996 \\
1.033-2.152 \\
0.963-1.640 \\
0.183-1.360 \\
0.673-1.783\end{array}$ \\
\hline $\begin{array}{l}\text { Medical comorbidities } \\
\text { Hypertension } \\
\text { Weight gain } \\
\text { Arthritis } \\
\text { Chronic obstructive } \\
\text { pulmonary disease } \\
\text { Cerebral vascular disease } \\
\text { Coronary heart disease } \\
\text { Dyslipidemia }\end{array}$ & $\begin{array}{l}1.636 \\
2.516 \\
0.920 \\
1.289 \\
1.223 \\
1.134 \\
1.844\end{array}$ & $\begin{array}{l}0.865-1.921 \\
0.702-2.129 \\
0.588-2.188 \\
0.813-4.182\end{array}$ \\
\hline
\end{tabular}

managed care enrollment, and the fact that some mental services may not have been billed to patients' managed care organizations. Finally, we identified comorbid conditions by diagnostic codes without considering the contribution of drugs to weight gain, hypertension, cerebral vascular disease, and other disorders.

Despite the above limitations, our study adds to the limited literature about diabetes risk in patients with bipolar disorder in managed care Medicaid programs. It provides useful information on disease management strategies in terms of selection of mood stabilizers and consideration of relevant comorbidities for patients with bipolar disorder, especially the managed care Medicaid population. Atypical antipsychotics provide great benefit to a wide variety of individuals with psychiatric disorders; nevertheless, they have a constellation of adverse effects related to increased risk for weight gain, diabetes, and dyslipidemia. ${ }^{10,11}$

\section{Conclusion}

The atypical antipsychotics olanzapine, risperidone, and quetiapine are consistently associated with increased risk for diabetes in patients with bipolar disorder after adjustment for relevant risk factors. Metabolic complications are a clinically important issue for patients receiving antipsychotic therapy. The choice of olanzapine, risperidone, or quetiapine for a specific patient with bipolar disorder should involve consideration of each agent's risks and benefits, with attention to comorbid conditions relevant to the patient's risk for diabetes. Thus, 
the propensity of an antipsychotic agent to induce or exacerbate diabetes is a critical consideration in the selection of an agent to treat bipolar disorder.

\section{Acknowledgment}

The authors would like to thank Sharmane Guo for her technical support and language edits.

\section{References}

1. Keck PE Jr, Marcus R, Tourkodimitris S, et al. A placebocontrolled, double-blind study of the efficacy and safety of aripiprazole in patients with acute bipolar mania. Am J Psychiatry 2003;160(9):1651-8.

2. Lieberman JA, Stroup TS, McEvoy JP, et al, for the Clinical Antipsychotic Trials of Intervention Effectiveness (CATIE) Investigators. Effectiveness of antipsychotic drugs in patients with chronic schizophrenia. N Engl J Med 2005;353(12):1209-23.

3. Al-Zakwani IS, Barron JJ, Bullano MF, et al. Analysis of healthcare utilization patterns and adherence in patients receiving typical and atypical antipsychotic medications. Curr Med Res Opin 2003;19(7):619-26.

4. Guo JJ, Keck PE, Li H, Jang R, Carson W. Evolution of mood stabilizer utilization among patients with bipolar disorder in a managed care Medicaid program [abstr]. Pharmacotherapy 2004;24(10): 1463 .

5. Keck PE Jr, McElroy SL. Aripiprazole: a partial dopamine $\mathrm{D}_{2}$ receptor agonist antipsychotic. Expert Opin Investig Drugs 2003;12(4):655-62.

6. Hirschfeld RM, Keck PE Jr, Kramer M, et al. Rapid antimanic effect of risperidone monotherapy: a 3-week multicenter, double-blind, placebo-controlled trial. Am J Psychiatry 2004:161(6):1057-65.

7. Moller HJ, Nasrallah HA. Treatment of bipolar disorder. J Clin Psychiatry 2003;64(suppl 6):9-17.

8. Mamo D, Kapur S, Shammi CM, et al. PET study of dopamine $\mathrm{D}_{2}$ and serotonin $5-\mathrm{HT}_{2}$ receptor occupancy in patients with schizophrenia treated with therapeutic doses of ziprasidone. Am J Psychiatry 2004;161(5):818-25.

9. Papakostas GI, Petersen TJ, Nierenberg AA, et al. Ziprasidone augmentation of selective serotonin reuptake inhibitors (SSRIs) for SSRI-resistant major depressive disorder. J Clin Psychiatry 2004;65(2):217-21.

10. American Diabetes Association, American Psychiatric Association. Consensus development conference on antipsychotic drugs and obesity and diabetes. Diabetes Care 2004;27(2):596-601.

11. Newcomer JW. Second-generation (atypical) antipsychotics and metabolic effects: a comprehensive literature review. CNS Drugs 2006;19(suppl 1):1-93.

12. Worrel JA, Marken PA, Beckman SE, Ruehter VL. Atypical antipsychotic agents: a critical review. Am J Health Syst Pharm 2000;57(3):238-55.

13. Keck PE, McElroy SL. Bipolar disorder, obesity, and pharmacotherapy-associated weight gain. J Clin Psychiatry 2003;64(12):1426-35.

14. Koro CE, Fedder DO, L'Italien GJ, et al. Assessment of independent effect of olanzapine and risperidone on risk of diabetes among patients with schizophrenia: population-based nested case-control study. BMJ 2002;325:243-8.

15. Fertig MK, Brooks VG, Shelton PS, English CW Hyperglycemia associated with olanzapine. J Clin Psychiatry 1998;59:687-9.

16. Lindenmayer JP, Patel R. Olanzapine-induced ketoacidosis with diabetes mellitus. Am J Psychiatry 1999;156:1471.

17. Rigalleau V, Gatta B, Bonnaud S, et al. Diabetes as a result of atypical antipsychotic drugs: a report of three cases. Diabet Med 2000;17:484-6.
18. Biswas PN, Wilton LV, Pearce GL, Freemantle S, Shakir SA The pharmacovigilance of olanzapine: results of a postmarketing surveillance study on 8858 patients in England. J Psychopharmacol 2001;15:265-71.

19. Roefaro J, Mukherjee SM. Olanzapine-induced hyperglycemic nonketonic coma. Ann Pharmacother 2001;35(3):300-2.

20. Colli A, Cocciolo M, Francobandiera F, Rogantin F, Cattalini N. Diabetic ketoacidosis associated with clozapine treatment. Diabetes Care 1999;22(1):176-7.

21. Mithat B, Alpaslan T, Bulent C, Cengiz T. Risperidoneassociated transient diabetic ketoacidosis and diabetes mellitus type 1 in a patient treated with valproate and lithium. Pharmacopsychiatry 2005;38(2):105-6.

22. Laghate VD, Gupta SB. Acute pancreatitis and diabetic ketoacidosis in non-diabetic person while on treatment with sodium valproate, chlorpromazine and haloperidol. J Assoc Physicians India 2004;52:257-8.

23. Miller EA, Leslie DL, Rosenheck RA. Incidence of new-onset diabetes mellitus among patients receiving atypical neuroleptics in the treatment of mental illness: evidence from a privately insured population. J Nerv Ment Dis 2005;193(6):387-95.

24. Leslie DL, Rosenheck RA. Incidence of newly diagnosed diabetes attributable to atypical antipsychotic medications. Am J Psychiatry 2004;161(9):1709-11.

25. Kornegay CJ, Vasilakis-Scaramozza C, Jick H. Incident diabetes associated with antipsychotic use in the United Kingdom general practice research database. J Clin Psychiatry 2002;62(9):758-62.

26. Hedenmalm K, Hagg S, Stahl M, Mortimer O, Spigset O Glucose intolerance with atypical antipsychotics. Drug Saf 2002;25(15):1107-16.

27. Tavakoli SA, Arguisola MS. Diabetic ketoacidosis in a patient treated with olanzapine, valproic acid, and venlafaxine. South Med J 2003;96(7):729-30.

28. Courvoisie HE, Cooke DW, Riddle MA. Olanzapine-induced diabetes in a seven-year-old boy. J Child Adolesc Psychopharmacol 2004;14(4):612-16.

29. Domon SE, Cargile CS. Quetiapine-associated hyperglycemia and hypertriglyceridemia. J Am Acad Child Adolesc Psychiatry 2002;41(5):495-6.

30. Dunner DL. Safety and tolerability of emerging pharmacological treatments for bipolar disorder. Bipolar Disord 2005; 7(4):307-25.

31. Koyanagi C, Forguer S, Alfano E. Medicaid policies to contain psychiatric drug costs. Health Aff (Milwood) 2005;24(2): 536-44.

32. Heisler M, DeMonner SM, Billi JE, Hayward RA. Medicaid managed care: are academic medical centers penalized by attracting patients with high-cost conditions? Am J Manag Care 2003;9(1):19-29.

33. Lambert BL, Chou CH, Chang KY, Tafesse E, Carson W Antipsychotic exposure and type 2 diabetes among patients with schizophrenia: a matched case-control study of California Medicaid claims. Pharmacoepidemiol Drug Saf 2005; 14:417-25.

34. Lund BC, Perry PJ, Brooks JM, Arndt S. Clozapine use in patients with schizophrenia and the risk of diabetes, hyperlipidemia, and hypertension: a claims-based approach. Arch Gen Psychiatry 2001;58:1172-6.

35. PharMetrics. PharMetrics patient-centric database: a large medical claims data source in US. Available from http://www.pharmetrics.com. Accessed August 1, 2004.

36. Wynn V. Effects of duration of low-dose contraceptive administration on carbohydrate metabolism. Am J Obstet Gynecol 1982;142:739-46.

37. Isojarvi JI, Rattya VV, Knip M, et al. Valproate, lamotrigine, and insulin-mediated risks in women with epilepsy. Ann Neurol 1998;43(4):446-51.

38. Wirshing DA, Boyd JA, Meng LR, et al. The effects of novel antipsychotics on glucose and lipid levels. J Clin Psychiatry 2002;63:856-65.

39. Chae BJ, Kang BJ. The effect of clozapine on blood glucose metabolism. Hum Psychopharmacol 2001;16:265-71. 
40. Procyshyn RM, Pande S, Tse G. New-onset diabetes mellitus associated with quetiapine. Can J Psychiatry 2000;45:668-9.

41. Sobel M, Jaggers ED, Franz MA. New-onset diabetes mellitus associated with the initiation of quetiapine treatment. J Clin Psychiatry 1999;60:556-7.

42. Lindenmayer JP, Nathan AM, Smith RC. Hyperglycemia associated with the use of atypical antipsychotics. J Clin Psychiatry 2001:62:30-8.

43. Takahashi M, Ohishi S, Katsumi C, Moriya T, Miyaoka H. Rapid onset of quetiapine-induced diabetic ketoacidosis in an elderly patient: a case report. Pharmacopsychiatry 2005; 38(4):183-4

44. Mamdani M. Antipsychotics and diabetes: is there an association? Pharmacoepidemiol Drug Saf 2005;14:403-5.

45. McIntyre RS, Mancini DA, Basile VS, Srinivasan J, Kennedy SH. Antipsychotic-induced weight gain: bipolar disorder and leptin. J Clin Psychopharmacol 2003;23:323-7.
46. Sachs GS, Guille C. Weight gain associated with use of psychotropic medications. J Clin Psychiatry 1999;60(suppl 21):16-19.

47. Koller EA, Cross JT, Doraiswamy PM, Schneider BS Risperidone-associated diabetes mellitus: a pharmacovigilance study. Pharmacotherapy 2003;23:735-44.

48. Jeppesen J, Hein HO, Suadicani P, Gyntelberg F. Triglyceride concentration and ischemic heart disease: an eight-year followup in the Copenhagen male study. Circulation 1998;97:1029-36.

49. Fleck DE, Keck PE, Corey KB, Strakowski SM. Factors associated with medication adherence in African American and white patients with bipolar disorder. J Clin Psychiatry 2005;66(5):646-52

50. Keck PE, McElroy SL, Strakowski SM, Balistreri TM, Kizer DI, West SA. Factors associated with maintenance antipsychotic treatment of patients with bipolar disorder. J Clin Psychiatry 1996;57(4):147-51. 